\title{
Letter
}

\section{Generalizations in the reintroduction literature: a reply to Armstrong \& Seddon}

In Bajomi et al. (2010) we presented the outcome of an extensive literature search to evaluate the extent, distribution and dispersal of the animal reintroduction literature. When comparing numbers of reintroduction programmes and resulting publications we found a significant taxonomic bias favouring birds and mammals. We recommended that editors and peer reviewers lessen the bias in scientific journals. We also stated that 'the dispersed and biased nature of the literature means that we may be failing to accumulate a reliable evidence base to underpin decision making'. In their response Armstrong \& Seddon (2011) state that 'we are not aware of any evidence of taxonomic bias in evaluation of reintroduction papers'. They also criticize two apparent assumptions they found in our research: 'knowledge in reintroduction biology is taxon-specific', and 'the literature consists of descriptive reports on reintroduction projects, which would lead to the expected correspondence between project characteristics (e.g. taxa featured) and publications'. They advocate a distinction between such reports and strategic question-based research.

An unconscious bias in the evaluation of scientific papers has been documented in ecology and behaviour: to be published, studies on ectothermic vertebrates had to be framed more conceptually than those on endothermic vertebrates (Bonnet et al., 2002). The fields of ecology and behaviour overlap with reintroduction biology; in our database on reintroduction literature (Bajomi et al., 2010) there are 25 articles published in the nine journals surveyed by Bonnet et al. (2002). Armstrong \& Seddon (2011) suggest that we do not have direct evidence of evaluation bias in the reintroduction literature, and the question is whether findings in neighbouring areas can be generalized to reintroductions. In our opinion the answer is yes, until the arrival of more direct evidence for or against. In the discussion of our paper (Bajomi et al., 2010) we proposed several other solutions to the problem of biased publication of reintroduction projects, in the form of new questions: further research should clarify these issues.

When formulating the conclusions of our article (Bajomi et al., 2010) we did not have in mind that 'knowledge in reintroduction biology is taxon-specific, i.e. reintroduction outcomes for a particular taxon will im- prove only with research on that taxon'. In contrast, we believe that generalizations across taxa can be deduced from the accumulated literature. This is why we are involved in the update of the Guidelines for Reintroductions (IUCN, 1998), which give general advice to practitioners without taxonomic restriction. However, Armstrong \& Seddon (2011) also admit that 'issues in reintroduction may be correlated with taxon'. When attempting generalizations it is important to incorporate such correlations into the theoretical framework.

Concerning our apparent second assumption that the literature consists of descriptive reports on reintroduction projects, we are aware of the difference between descriptive reports and strategic question-based research but did not consider this distinction in our research. We are grateful to Armstrong \& Seddon (2011) for calling our attention to this. Research on model systems that generate more publications than expected could be a factor explaining the publication bias that we found.

We think we can reach an agreement with Armstrong \& Seddon (2011) that we don't need either to treat research as taxon-specific or naively generalize research across taxa, i.e. there is a middle ground that would be more sensible. That would be a theoretical framework taking into account key factors such as size, metabolic rate and dispersal ability, and treating clades as random effects.

\section{BÁLINT BAJOMI (Corresponding author) and ANDRÁS \\ TAKÁCS-SÁNTA \\ Centre for Environmental Science, Eötvös Loránd University of Sciences, Pázmány P. s. 1/A, 1117 Budapest, Hungary \\ E-mailbb@greenfo.hu}

\section{References}

Armstrong, D.P. \& Seddon, P.J. (2011) Making inferences from the reintroduction literature: a response to Bajomi et al. Oryx, 45,18 .

Bajomi, B., Pullin, A.S., Stewart, G.B. \& Takács-Sánta, A. (2010) Bias and dispersal in the animal reintroduction literature. Oryx, 44, 358-365.

Bonnet, X., Shine, R. \& Lourdais, O. (2002) Taxonomic chauvinism. Trends in Ecology \& Evolution, 17, 1-3.

IUCN (1998) Guidelines for Re-introductions. IUCN/Species Survival Commission Re-introduction Specialist Group, Gland, Switzerland. Http://www.iucnsscrsg.org/download/English.pdf [accessed 10 November 2010]. 